from intellectual aptitude, the intelligent and the dull being equally liable to commit the errors in the forms which will hereafter be specified.

Consideration will first be given to the existence of general laws, of which there appear to be three, so strongly marked as to stand clearly distinguishable as including in themselves the minor manifestations. These laws are as follows :-

(I) There is a general law making us fundamentally incapable of drawing in perspective. It is a radical condition-not of ignorance of the laws of perspective but of active negation of them. It is a natural necessity to show by the arrangement of lines the exact contrary to true perspective. It is persistent, and exists long after correct knowledge of the true arrangement of the lines is acquired, and the error is always liable to appear on any occasion of forgetfulness--that is to say, when drawing is not done with the true principles immediately in remembrance in the mind. It is perceivable in the form of direct divergence of lines (parailel in nature) which in perspective should converge to their vanishing point.

(2) Another general law is a natural incapacity to erect a proper perpendicular for an object unless the same occurs close on the line of direct sight (forward). If the perpendicular be situate laterally, and especially if it be short, it is liable to a deflection. This deflection occurs in the following manner :-If the same be on the right hand the line inclines from its top towards the central line of sight (forward) ; its foot is therefore nearer this central line than its top. On the left hand the phenomena are directly reversed. This error occurs whether the perpendicular be the obvious physical corner line of a solid or whether it be the integral (invisible) line of any such solid or of a drawn figure.

(3) The next general law is less distinct, but still abundantly provable on test. It affects those lines which, being in right angles to the observer, lie laterally to him; that is to say, if a line of the surface (horizontal) of a figure occur on the right or left hand, at a little distance, the line is not drawn with perspective inclination to the vanishing point in front o! the ohserver, but is drazen as a perpendzcular, or, as is evident, in such a manner as would be the true fact of its direction, void of the influence of perspective. Thus, if a square lie two or three feet to right or left of the draughtsman, those two sides of it which are the sides rectilinear, not sides parallel to the base of the picture-plane, are drawn as two perpendiculars, while they should be converging lines towards a point which leads them diagonal-wise across the paper.

These brief particulars are intended to give an account of the primary, or general, laws. All other manifestations are deducible from them - that is, in every case where a special aspect of a figure draws out its special error, this is seen to have its origin in one or other of these three primary laws. From this point I now proceed to illustrate with examples selected from three figures-the cube, the pyramid, and the hexagon-instances of special error. Other geometrical figures may at a future period be likewise illustrated, but the intention is in this paper only to broach the subject.

\section{The Cube.}

It is in all cases assumed the object lies on a table before the observer.

Pusition I. - Let the cube be placed on the right or left, and with two planes parallel to the picture-plane, two in right angles.

Error 1.-The perpendiculars will be inclined as radiants upwardly.

Error 2. -The 3 perspectives visible will diverge.

Error 3.-Or these will be neutralised of perspective, and the true perpendiculars be inclined.

Position 2. - Let the cube be situate anglewise on the direct line of sight.

Error 1.-All 6 perspectives to right and left diverge.

Error 2. - Or the top is drawn as a square.

Position 3.- Poise the cube on an edge, so that one plane, resting exactly balanced on its corner, is in the direct front, and parallel to picture-plane.

Error 1.-The perspectives (3) will diverge.

Error 2.-The square of the front plane will be confused as rhomboidal.

Position 4.-Still having the cube poised on an edge, let it be turned so that three faces are seen at one time, and it presents perspectives in 9 lines.

No. 1243 . VOL. 48 ]
Error I.-All the perspectives, in groups of 3 each, for each plane, will diverge.

\section{The Pyramid (Square)}

Position 1. - Let the pyramid lie exactly in front, parallel to the picture-plane.

Error I. - The two parallel edges of the square base, extending in right angles from the eye, will diverge.

Error 2. - The further side of the pyramid will thus be longer than the nearer side.

Position 2. - Let the pyramid lie on the same spot, but with an angle presented, so that the sides of the square extend in equal angles.

Error I. - If the view of it should be isometrical, or the pyramid flattish, the perspectives will be shown diverging.

Position 3.-Place the pyramid point downwards towards the observer, in front, and with one side for a base.

Error I. - The two parallel retiring lines of the inclined real base will show divergence.

Error 2.-Consequently, the further line of base will be longer than the nearer and upper of this sloping square.

Position 4.-Place the pyramid so that it still lies on a side for a base, but in front, and the apex and the central point of a side of the real base are on a line parallel to picture-plane.

Error 1. - The apex, which should thus lie horizontally $c v . n$ with the central point of that line of real base, which touches the ground, will be shown below that line. The true relation to central point given is rever seen.

Error 2.-Such perspectives as occur will diverge.

\section{The Hexagor.}

Position 1.-Place a solid hexagon upright in the exact front of observer, with two planes parallel to picture-plane.

Error I.-All perspectives of the parallel sides will diverge.

Error 2.-Consequently, the two parallel lines (integral) which connect opposite angles of the hexagon will lose their perspective.

Position 2. - Place the hexagon on a side, so that its lines, then horizontal, are parallel to picture-plane and the object is in a lat. eral situation, or not in front.

Error I. The end, which is now a plane in right angles, will show the integral connecting lines between top and bottom angles leaning, because these are essentially perpendicular therefore the perpendicularity is distorted. (General law I.)

Error 2.- The line (integral) connecting the two angles mid. way between top and base line of this plane, and which should be of course parallel to these, and partaking of their perspective, will have a course diagonal to them, always, deflecied downwards.

Error 3.- The lines which indicate the further, or unseen plane of hexagon will show exact conformity to this error; also diverging perspective.

Position 4.- - Place the hexagon again laterally, with its end as a front plane, and a side on the ground, the direction of the object being in a due rectilinear line.

Error 1. - The perspective bias will be lost (general law 3) and the lines traced as perpendiculars.

Error 2.-Or these will indicate divergence in place of convergence.

Error 3.-The plane parallel to picture-plane, and essenitially void of distortion, will be nevertheless distorted.

P'osition 3.-Place the hexagon, still resting on a side, so that its lines take a diagonal line with regard to a line parallel to the picture plane, and it must be in front.

Error 1. - The displacement of the integral perpendicular. will occur in the end planes, as in Error I of Position 2.

Error 2. - The Error 2, in Position 2, will be repeated.

Error 3. - The perspectives will diverge.

ARTHUR I.. HaDdon.

\section{THE DEPARTMENT OF SCIENCE AND ART.}

THE fortieth Report of the Department of Science and Art has just been issued, and is of a highly satisfactory character. From it we learn that in 1892 there was a very large increase, not only in the number of students and classes, but also in the number of schools or separate institutions in which science is taught. The number of classes in different branch _s of science in 1892 was 10,352 , as against 8,568 in the preceding year, and 
the number of pupils under instruction showed the remarkable increase of 32,002 , the totals for 1891 and 1892 being respectively 148,408 and 180,410 . The number of examination papers worked was 203,347 , and the number of individual examinees 108,858 , so there was an average of nearly two papers for each student. The greatest number of papers, $29,05 \mathbf{I}$, was worked in mathematics. In physiography, 21,944 papers were written, and in theoretical inorganic chemistry, $2 \mathrm{I}, 578$ papers. The lowest number of candidates were presented in mineralogy and nautical astronomy, the number of papers worked in these subjects being 119 and I4I respectively. With regard to the extent to which local authorities are devoting funds for the purposes of science, art, technical, and manual in struction, it is reported that "Of the forty-nine councils of counties in England (excepting Monmouth), forty-two are now giving the whole of the residue to technical education, while the remaining seven are giving a part of the amount ; and of the sixty-one councils of county boroughs, fifty are devoting the whole of the residue to the same purpose, and ten are devoting a part of it, no decision having yet been arrived at in the case of Great Grimsby (which it may be mentioned was only constituted a county borough on April r, 189I). Of the councils of the sixteen counties and county boroughs of Wales and Monmouth, to which the Welsh Intermediate Education Act, 1889, applies, fifteen are applying the whole of the residue to the purposes of intermediate and technical education, and one a part of it. Contributions are also made out of the rates under the Technical Instruction Act, I889, in the case of seven counties and county boroughs in Wales and Monmouth. As regards Scotland, so far as returns have been received, the whole of the residue fund is being applied to technical education in the case of twenty counties (out of thirty-three) and sixteen burghs and police $t$ urghs (out of 187), while six counties and thirty-nine burghs and police burghs are giving part of it to the same purpose. Of the remainder, the majority of the local authorities are devoting the residue to the relief of rates, and a small proportion of them have under consideration the question of applying the money to technical education."

In conclusion, it is pointed out that "the opportunities afforded to people engaged in all branches of industry for acquiring a knowledge of much which is closely connected with their daily work, but which cannot be obtained in the factory or workshop, are constantly increasing. The municipal schools, which are steadily growing in number and efficiency in all parts of the country, must be of great service in this connection. Further, in proportion as local interest is developed, and em. ployers show that they value sound scientific instruction and art teaching, the effectiveness of these schools will be promoted But whether the income of these schools be derived mainly from local or Imperial sources, it is essential that the course of instruction adopted shall be well adapted to the needs of the town or district. The more fully the educational welfare of the students takes the first place, and the mere earning of Government grants the second place in the new Municipal schools, the more certainly will they fulfil their object."

It is clear from this that the Department desires to stamp out the system whereby science classes are "farmed" by teachers. The acquisition of knowledge is rightly regarded as the proper goal, not the mere obtaining of a certificale. The technical instruction committees of some of the county councils would do well to bear this and the following admonition in mind "Without a sound foundation of general education, the highest scientific training cannot be imparted ; without a sufficient supply of teachers with adequate salaries, who are not overworked and who not merely know their subject, but know how to teach it, a considerable part of the money expended on the encouragement of new forms of education must be wasted."

\section{EUROPEAN LABORATORIES OF MARINE BIOLOGY.}

Y $A$ RINE laboratories are now recognised as essential to the progress of biology. The facilities they offer the collector and the investigator cannot be overrated, and it would be an excellent thing if institutions could be conducted on similar lines in every branch of science. Mr. Bashford Dean, in the American Naturalist of July, gives an illustrated description of marine laboratories in Europe, which is so interesting that a large portion of it is here reprinted. The description of the
Marine Biological Station at Plymouth is omitted owing to the fact that a detailed account has already appeared in these columns (vol. xxxviii. p. 198, 1888). Mr. Dean prefaces his report as follows :-

"In every country the marine laboratory has become a need of the student of biology. During his winter studies in the university it serves to provide bim with well-preserved material, often with living forms which he may himself prepare according to his wants; in summer it gives him opportunily to see and collect his study types, and utilise with profit and withou physical discomfort abundant material relating to his studies. To the investigator the marine laboratory has become, in the broadest sense, a university. $\mathrm{He}$ may there meet the representative students of far and wide, fellow-workers, perhaps, in the very line of his own research, and must bimself, unknowingly, teach and learn. He finds out gradually of recent work, of technical methods which often happen most pertinent to his present needs. He may carry on nis work quietly and thoroughly; his works of reterence are at hand; he has the most necessary comfort in working-the feeling of physical rest, untroubled by the rigid hours of demonstrations and lectures.

"The importance of the work of the marine laboratory has been keenly appreciated in foreign countries, and it is noteworthy how large a number of the original researches is at present conducted at, or upon material from, these distributing centres of biology. At the present day the entire coast line of Europe has become dotted with zoological stations great and small, grown out of the resources granted by societies, private individuals, or governments-perhaps by the combined efforts of all. It is a matter of great interest to note how thoroughly the marine laboratory system abroad had become a part of every grade of biological work. The student in a small university in the interior of France receives his first lessons from material sent regularly from Roscoff or Banyuls. He examines living sponges, hydroids, lucernarians, pennatulids, beroës, Loxosoma Comatula, and Amphioxus. In Munich, hundreds of miles from the sea, is another example. Prof. Richard Hertwig, by the aid of material from Naples, demonstrates the larval character of ascidians, or the fertilisation of the egg of the sea urchin. Every group of European universities seems to have centralised its marine biological work in a convenient locality, and this branch of their needs is supported-and is well supported-even in countries whose financial resources are most limited. The importance of this work is felt to such a degree that it is not from reasons unselfish that universities have united in their sup port of a station like that of Naples. This has become literally an emporium cosmopolitan, bringing together side by side, perhaps not unnaturally, the best workers of many universitie whose observations upon the best material, sharpened by dis. cussion and criticism, are certainly tending to become the most accurate and the most fruitful in their direction and results.

"It is most singular that foreign countries are unquestion. ingly liberal in the support of pure biology, and in the work of marine stations the tendency is becoming less and less on the part of money-givers to ask how many fish will be hatched to become food material. Public interest has been gradually com ing to be directed to the general laws and the problems of life and heredity. This has well been a hopeful sign, and the European biologists are not backward in emphasising the im. portance of their studies. Prof. de Lacaze-Duthiers does not hesitate even to propitiate the practical Cerberus, reminding him how often 'facts have been found at every step of science which were valueless at their discovery, but which, little by little, fell into line and led to applications of the highest importancehow the observation of the tarnishing of silver, or the twitching leg of the frog, was the origin of photography and telegraphyhow the purely abstract problem of spontaneous generation gave rise to the antiseptics of surgery."

Beginning with the marine laboratories of France, Mr. Dean says :-

"The extended sea coast has ever been of the greatest aid to the French student-along the entire northern coast the channel is not unlike the Bay of Fundy in the way it sweeps the waters out at the Iunar tides. The rocks on the coast of Brittany, massive boulders, swept and rounded by the rushing waters, will, at these times become exposed to a depth as great as $4^{0}$ feet. This is the harvest-time of the collector; he is enabled to secure the animals of the deep with his own hand, to take them carefully from the rocky crevices where they would ever have avoided the collecting dredge. From easliest times this

NO. I 243 , voL. 48] 